\title{
Bending Beam Measurement of Moisture Diffusion in Polyimide Films on Silicon Substrate
}

\author{
Jwo-Huei Jou, Li Hsu, Peir-Teh Huang, Rita Huang,* \\ and Wen-Ping SHEN** \\ Department of Materials Science and Engineering, Tsing Hua University, \\ Hsin Chu, Taiwan 30043, R.O.C.
}

(Received January 5, 1991)

\begin{abstract}
A theoretical model, correlating the bending curvature variation ratio of a layered structure caused by moisture-induced-swelling in its polymer overcoat with time under Case I diffusion, has been developed. This model has considered the pre-existing intrinsic strain in the polymer film upon deposition. According to this model, any specimen to be studied does not need to be bending or strain free. Furthermore, an useful and relatively simplified formula has been derived therefrom and used in identifying the diffusions of moisture in the films of two rod-like and one semi-flexible polyimides, their blends, and a random copolyimide. In PMDA-ODA (pyromellitic dianhydride-4,4'-oxydianiline), the diffusion constant, $D$, is $4.64 \times 10^{-9} \mathrm{~cm}^{2} \mathrm{~s}^{-1}$. In PMDA-PDA ( $p$-phenylenediamine), $D=1.25 \times 10^{-9}$, and in PMDA-B (-benzidine) $0.10 \times 10^{-9}$ $\mathrm{cm}^{2} \mathrm{~s}^{-1}$. The diffusion fastest in PMDA-ODA can be attributed to its amorphous structure, and slowest in PMDA-B to its small interchain spacing. The diffusion in a random copolymer with $50 \mathrm{wt} \%$ PMDA-PDA and $50 \mathrm{wt} \%$ PMDA-B is faster than in the blend with $60 \mathrm{wt} \%$ PMDA-PDA and $40 \mathrm{wt} \%$ PMDA-B. This can be attributed that the random copolyimide film is more amorphous according to an X-ray diffractometry study.

KEY WORDS Moisture Diffusion / Case I Diffusion / Bending Beam Technique / Polyimide Films / Silicon Substrate /
\end{abstract}

Polyimide films exhibit excellent mechanical properties, low dielectric constant, high glass transition, and low thermal expansion. ${ }^{1,2}$ They can be used as interlayer dielectrics, $\alpha$-particle protection coating, and thermal-mechanical buffer layers in microelectronic devices. ${ }^{3-7}$ However, in a humid environment, moisture uptake may degenerate the physical properties of polyimide films and cause several serious problems to devices. ${ }^{8-10}$ Hence, there is a definite need to understand the diffusion mechanism of moisture in these films.

Though there have been several techniques available for the measurements of solvent diffusions in polymers, ${ }^{11-17}$ techniques for moisture or water diffusion determination are quite limited. ${ }^{18-20}$ For example, in most polyimide films, the maximum uptake moisture contents are not higher than a few percents. Unlike in most solvent diffusions, such a small change in weight upon moisture uptake is difficult to measure accurately, if not impossible. However, a bending beam technique has been successfully applied in the measurements of moisture diffusion in epoxy coatings ${ }^{19}$ and water diffusion in polyimide films. ${ }^{21}$ The latter ones also include the measurements of water diffusion in rod-like polyimide films that could

\footnotetext{
* Present address: Materials Research Laboratories, Industrial Technology Research Institute, Hsin Chu, Taiwan 31015, R.O.C.

** Present address: Department of Chemical Engineering, Syracuse University, 107 Roney Lane \#11, Syracuse, NY 13210, U.S.A.
} 
be too fragile for other techniques. Though this technique is a relatively sensitive one, it could be hardly claimed a very convenient method due to its mathematical complications in case of Case I diffusion.

To eliminate the drawback, a relatively simplified formula has been derived from a newly developed theoretical model. As will be demonstrated later, the formula can be used easily in the calculation of diffusion constant in case of Case I. In the model, intrinsic strain, which exists in nearly any polymer film on substrate upon casting and/or curing, has been also taken into account. This should make the bending beam technique more useful in diffusion measurements, since most polymer coated substrates are not bending free due to the pre-existed intrinsic strain in the polymer layer.

By using the simplified formula, the diffusion constants of moisture in the films coated on silicon substrates, of two rigid rod-like and one semi-flexible polyimides, their blends, and one random copolyimide have been determined. These results will be presented later. The polyimides studied are PMDA-ODA (pyromellitic dianhydride-4,4'-oxydianiline), PMDA-PDA (pyromellitic dianhydride- $p$-phenylenediamine), and PMDA-B (pyromellitic benzidine).

\section{THEORY}

In this model, a bilayer structure composing a flat substrate and a thin layer of polymer overcoat is considered. This model correlates the variation of bending curvature of the bilayer structure caused by solvent uptake induced swelling in the polymer film with the diffusion of a given solvent or water under Case I condition. To establish the model, there are at least two approaches. In the first approach, the balance of internal forces established is based on an assumption that ignoring any solvent concentration distribution inhomogeneity, the polymer film can be treated as a single layer uptaking an uniform concentration of solvent throughout the film at a given diffusion time. ${ }^{19}$ The effect of any inhomogeneously distributed concentration on the structure bending curvature is then corrected in the balance equations for interfacial strains and moments. In our approach, the polymer layer is first divided into many differential thin sublayers according to its concentration distribution. Each sublayer may contain a different concentration. The balance equations of internal forces, interfacial strains and moments are then established accordingly.

It will be seen that both approaches give the same result. However, our model is established according to an approach widely applied in several other models for multilayer structures. $^{22-25}$ It might therefore provide readers a more clear understanding about the development of the model. Furthermore, in our approach, before diffusion process, the initial bending curvature of the structure or the intrinsic strain in the polymer layer upon coating and/or curing has been taken into account. This has not been considered in the former approach, though. In the following section, derivation details of our model are given.

\section{Bending Curvature-Diffusant Concentration Correlation}

First, the polymer film is divided into $(N-1)$ sublayers, each with a thickness of $d_{\mathrm{f}} /(N-1)$, as illustrated in Figure 1. " $d_{\mathrm{f}}$ " denotes the thickness of the film. " 1 " is denoted for the substrate. In the $i$ th sublayer, its concentration. is denoted as $C_{i}$

\section{Force Balance}

For this stucture, the internal forces in the $N$ layers must be balanced at a given diffusion time.

$$
\sum_{i=1}^{N} F_{i}=0 \quad i=1, N
$$

\section{Interface Strain Balance}

At the interface, the strain changes in any two neighboring layers are equal. 


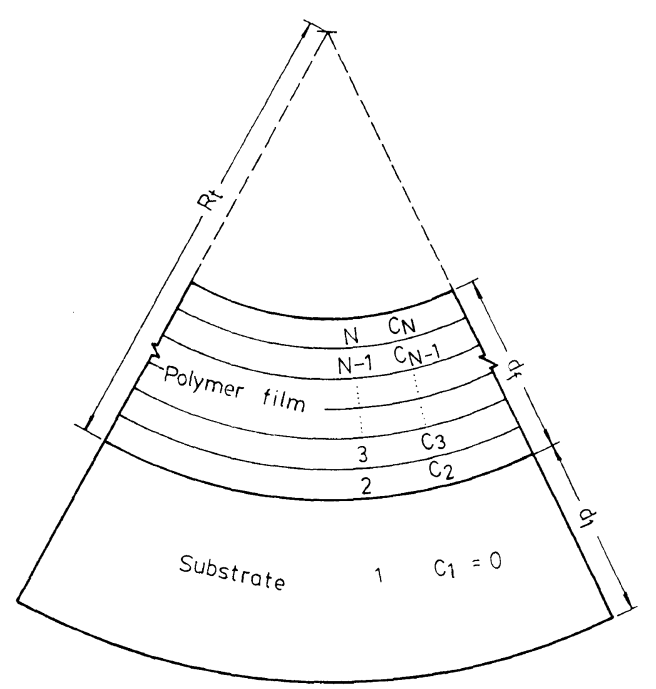

Figure 1. Schematic diagram of a layered substrate coated with a polymer film upon moisture diffusion. The film is divided into $N-1$ sublayers, each with a thickness of $d_{\mathrm{f}} /(N-1)$.

$$
\begin{aligned}
& \varepsilon_{\mathrm{l}, i}+\varepsilon_{\mathrm{H}, i}+\frac{F_{i}}{W d_{i} E_{i}^{*}}-\frac{d_{i}}{2 R_{t}}= \\
& \varepsilon_{\mathrm{I}, i+1}+\varepsilon_{\mathrm{H}, i+1}+\frac{F_{i+1}}{W d_{i+1} E_{i+1}^{*}}+\frac{d_{i+1}}{2 R_{t}}
\end{aligned}
$$

where $E_{i}^{*}$ denotes the biaxial modulus, $E_{i} /\left(1-v_{i}\right)$, and $E_{i}$ and $v_{i}$ Young's modulus and Poisson's ratio of the $i$ th layer. " $W$ " is for width. $\varepsilon_{1}$ is the time-independent intrinsic strain of the polymer film upon deposition prior to diffusion. $\varepsilon_{\mathbf{H}}$ is the time-dependent hydroscopic strain of the film upon solvent uptake and may increase with the increase of the magnitude of the uptaken solvent concentration. If it is constantly proportional to the absorbed concentration over the entire range, it can be defined as

$$
\varepsilon_{\mathrm{H}}(t)=S C(t)
$$

where $C(t)$ is the solvent concentration at a given diffusion time, $t$, and $S$ is the linear swelling parameter of the polymer film in the plane direction. Equation 3 will be no longer valid if swelling of the polymer film is a nonlinear function of sovlent concentration. This is very unlikely to occur if the "solvent" used is a non-solvent and has no plasticizing effect to the polymer.

In this paper, the studied "solvent" or penetrant is moisture, which is a non-solvent to the polyimides studied. Furthermore, the maximum moisture sorption contents of the studied polyimide films at $55 \%$ relative humidity are less than $2 \%$. Within a relative small solvent coancentration range, the relationship between the hygroscopic strain and solvent concentration could hardly be nonlinear. For example, as indicated by the results presented by Inoue et al., ${ }^{26}$ the equilibrium swelling vs. moisture regain of a nylon 6 film shows a fairly good linear relationship for moisture regains less than $3 \%$. However, if the diffusion in a given polymer/solvent system does not obey the relationship of eq 3 , the following derivation and the final analytical formula given hereafter should be modified further.

From eq 1 and 2, internal force in the $i$ th layer can be obtained.

$$
F_{i}=\frac{W d_{i} E_{i}^{*} \sum_{j=1}^{N} d_{j} E_{j}^{*}\left(\left(\frac{1}{R_{t}}\right)\left(\left(d_{i}+2 \sum_{k<i} d_{k}\right)-\left(d_{j}+2 \sum_{k<j} d_{k}\right)\right)+\sum_{k<i} L_{k}-\sum_{k<j} L_{k}\right)}{2 \sum_{j=1}^{N} d_{j} E_{j}^{*}}
$$

where the lumped constant, $L_{k}$, is given by

$$
\begin{gathered}
L_{k}=2\left(B_{k+1}-B_{k}\right) \\
B_{\mathrm{m}}=\varepsilon_{\mathrm{l}, \mathrm{m}}+\varepsilon_{\mathrm{H}, \mathrm{m}}
\end{gathered}
$$




\section{Moment Balance}

The total moments from all the internal forces must be counter-balanced by the bending moments as following,

$$
\sum_{i=1}^{N} M_{i}+\sum_{i=1}^{N} F_{i}\left(\frac{d_{i}}{2}+\sum_{j<i} d_{j}\right)=0
$$

where

$$
M_{i}=\frac{W E_{i}^{*} d_{i}^{3}}{12 R_{t}}
$$

From the moment balance equation, the radius of bending curvature, $R_{t}$, at any given time can be obtained in terms of the differential hygroscopic strains at different positions transversing the film. This is done by substituting eq 4 into eq 5 . One then obtains

$$
\frac{1}{R_{\mathrm{t}}}=\frac{6 \sum_{i=1}^{N} d_{i} E_{i}^{*}\left(\left(\frac{d_{i}}{2}+\sum_{j<i} d_{j}\right) \sum_{k=1}^{N} E_{k}^{*} d_{k}\left(\sum_{l<i} L_{l}-\sum_{l<k} L_{l}\right)\right)}{\sum_{i=1}^{N} d_{i} E_{i}^{*}\left(\sum_{j=1}^{N} d_{j}^{3} E_{j}^{*}+6\left(\frac{d_{i}}{2}+\sum_{j<i} d_{j}\right) \sum_{k=1}^{N} E_{k}^{*} d_{k}\left(d_{i}+2 \sum_{l<i} d_{l}\right)-\left(d_{k}+2 \sum_{l<k} d_{l}\right)\right)}
$$

From this equation, the intial bending curvature, $1 / R_{0}$, can be obtained as a function of the intrinsic strain and the pre-absorbed moisture concentration, if any, as followed,

$$
\frac{1}{R_{0}}=\frac{6 d_{1} E_{1}^{*} d_{\mathrm{f}} E_{\mathrm{f}}^{*}\left(d_{1}+d_{\mathrm{f}}\right)\left(\varepsilon_{\mathrm{l}, \mathrm{f}}+S C_{0}\right)}{\left(d_{1} E_{1}^{*}+d_{\mathrm{f}} E_{\mathrm{f}}^{*}\right)\left(d_{1}^{3} E_{1}^{*}+d_{\mathrm{f}}^{3} E_{\mathrm{f}}^{*}\right)+3 d_{1} E_{1}^{*} d_{\mathrm{f}} E_{\mathrm{f}}^{*}\left(d_{1}+d_{\mathrm{f}}\right)^{2}}
$$

where $C_{0}$ is the pre-absorbed moisture concentration by the film. The bending curvature at equilibrium, $1 / R_{\infty}$, can be expressed as

$$
\frac{1}{R_{\infty}}=\frac{6 d_{1} E_{1}^{*} d_{\mathrm{f}} E_{\mathrm{f}}^{*}\left(d_{1}+d_{\mathrm{f}}\right)\left(\varepsilon_{\mathrm{l}, \mathrm{f}}+S C_{\infty}\right)}{\left(d_{1} E_{1}^{*}+d_{\mathrm{f}} E_{\mathrm{f}}^{*}\right)\left(d_{1}^{3} E_{1}^{*}+d_{\mathrm{f}}^{3} E_{\mathrm{f}}^{*}\right)+3 d_{1} E_{1}^{*} d_{\mathrm{f}} E_{\mathrm{f}}^{*}\left(d_{1}+d_{\mathrm{f}}\right)^{2}}
$$

where $C_{\infty}$ is the final concentration.

For convenience, a dimensionless bending curvature variation ratio, $\Omega$, is used and defined as

$$
\Omega=\frac{1 / R_{t}-1 / R_{0}}{1 / R_{\infty}-1 / R_{0}}
$$

The bending curvature variation ratio can be further manipulated to give a much more useful formula as shown below, if $N$ approaches infinity.

$$
\Omega=\frac{1}{1+\frac{d_{\mathrm{f}}}{d_{1}}} \int_{0}^{1} \frac{C_{\mathrm{t}}-C_{\mathrm{o}}}{C_{\infty}-C_{\mathrm{o}}} \mathrm{d} u
$$

$$
+\frac{2}{1+\frac{d_{1}}{d_{\mathrm{f}}}} \int_{0}^{1} \frac{C_{t}-C_{\mathrm{o}}}{C_{\infty}-C_{\mathrm{o}}} u \mathrm{~d} u
$$

$$
+\frac{2 E_{1}^{*}}{\left(1+\frac{d_{1}}{d_{\mathrm{f}}}\right)\left(\frac{d_{1}}{d_{\mathrm{f}}}\right) E_{f}^{*}} \int_{0}^{1} \frac{C_{t}-C_{\mathrm{o}}}{C_{\infty}-C_{\mathrm{o}}} u \mathrm{~d} u
$$$$
\frac{E_{1}^{*}}{\left(1+\frac{d_{1}}{d_{\mathrm{f}}}\right)\left(\frac{d_{1}}{d_{\mathrm{f}}}\right) E_{\mathrm{f}}^{*}} \int_{0}^{1} \frac{C_{t}-C_{\mathrm{o}}}{C_{\infty}-C_{\mathrm{o}}} \mathrm{d} u
$$$$
=\int_{0}^{1} \frac{C_{\mathrm{t}}-C_{\mathrm{o}}}{C_{\infty}-C_{\mathrm{o}}} \mathrm{d} u+K \int_{0}^{1} \frac{C_{\mathrm{t}}-C_{\mathrm{o}}}{C_{\infty}-C_{\mathrm{o}}}
$$$$
\times\left(u-\frac{1}{2}\right) \mathrm{d} u ; \quad u=\frac{z}{d_{\mathrm{f}}}
$$ 
where $0 \leq z \leq d_{\mathrm{f}}$. " $z$ " is set to be equal to zero at the polymer-substrate interface. Also,

$$
K=\frac{2}{\left(1+\left(d_{1} / d_{f}\right)\right)}\left(1+\left(\frac{d_{\mathrm{f}}}{d_{1}}\right)\left(\frac{E_{f}^{*}}{E_{1}^{*}}\right)\right)
$$

In most cases, the tensile modulus of a deposited polymer film is much smaller than that of the substrate, such as silicon. If the thickness of the polymer film is smaller than the substrate, the term with tensile modulus can be ignored and $K \approx 2 \mathrm{~d}_{\mathrm{f}} /\left(d_{\mathrm{f}}+d_{1}\right)$.

Though taking the initial intrinsic strain into consideration, the resulting formula is still the same as that obtained by Berry et al. ${ }^{19}$ This means that to use such a bending beam technique to measure Case I diffusion constant, the specimen to be studied needs not be bending or strain free. In practice, it is not easy, if not impossible, to prepare a bending or strain free specimen.

In the following section, the bending curvature ratio will be further correlated to the diffusion constant in a Case I diffusion.

\section{Curvature Variation-Diffusion Constant Corre- lation}

In the following derivations, a concentration-independent diffusion constant is assumed. This may be a resonable assumption for the present systems since all the polyimide studied are typical high glass transition polymers and would not be plasticized by moisture. Besides, the moisture uptake contents of these polyimide films are relatively small, as mentioned above. Similarly, within a relative small concentration range, any concentration gradient formed in the systems should consequently be low and the diffusion coefficient investigated should remain unvaried or vary insignificantly with respect to concentration even if it depends on concentration. If a concentration-dependent diffusion coefficient in a given system is to be determined, the derivation hereafter should be modified. However, this is beyon the scope of this study. Here, the derivation is based on a Case I diffusion with a concentration-independent diffusion coefficient.

$$
\frac{\partial C}{\partial t}=D \frac{\partial^{2} C}{\partial z^{2}} \quad 0 \leq z \leq d_{\mathrm{f}}
$$

I.C. $C=C_{0}=0$

B.C. 1. $C=C_{\infty} \quad$ at $z=d_{\mathrm{f}} \quad$ for $t \geq 0$

2. $\frac{\partial C}{\partial z}=0 \quad$ at $z=0$ for $t \geq 0$

where $D$ is the diffusion coefficient of solvent or water in the film.

From eq 10, the solvent concentration solved by using a method of separation variable can be expressed as $^{27}$

$$
\begin{aligned}
\frac{C_{\infty}-C_{t}}{C_{\infty}-C_{\mathrm{o}}}= & 1-\frac{C_{t}-C_{\mathrm{o}}}{C_{\infty}-C_{\mathrm{o}}}=\sum_{n=0}^{\infty}(-1)^{n} \frac{4}{(2 n+1)} \\
& \times \exp \left(-\frac{(2 n+1)^{2}}{4} \pi^{2} \frac{D}{d_{\mathrm{f}}} t\right) \\
& \times \cos \left(\frac{(2 n+1)}{2} \pi \frac{z}{d_{\mathrm{f}}}\right)
\end{aligned}
$$

By substituting this expression back into eq 9 and without further integration, a theoretical curve for the curvature variation ratios at different times can be generated numerically. A best-fit diffusion constant can then be obtained from curve fitting on a trial-and-error basis, as presented in an earlier paper. ${ }^{21}$ By substituting eq 12 back into eq 9 and after integration, a more simplified form for the curvature variation ratio can be reached

$$
\begin{aligned}
\Omega= & -\left(1+\frac{K}{2}\right) \sum_{n=0}^{\infty} \frac{8}{(2 n+1)^{2} \pi^{2}} \\
& \times \exp \left(-\frac{(2 n+1)^{2}}{4} \pi^{2} \frac{D}{d_{\mathrm{f}}} t\right) \\
& +K \sum_{n=0}^{\infty} \frac{16(-1)^{n}}{(2 n+1)^{3} \pi^{3}} \\
& \times \exp \left(-\frac{(2 n+1)^{2}}{4} \pi^{2} \frac{D}{d_{\mathrm{f}}} t\right)
\end{aligned}
$$


With this form, a similar complicated numerical computation is still required.

On the contrary, an useful approximated form can be reached by solving the solvent concentration via a Laplace transformation, ${ }^{27}$

$$
\begin{gathered}
\frac{C_{t}-C_{0}}{C_{\infty}-C_{0}}=\sum_{n=0}^{\infty}(-1)^{n} \operatorname{erfc}\left(\frac{(2 n+1) d_{\mathrm{f}}-z}{2(D t)^{1 / 2}}\right) \\
+\sum_{n=0}^{\infty}(-1)^{n} \operatorname{erfc}\left(\frac{(2 n+1) d_{\mathrm{f}}+z}{2(D t)^{1 / 2}}\right)
\end{gathered}
$$

By substituting this expression back into eq 9 , one has

$$
\begin{aligned}
& \Omega= 2\left(1+\frac{K}{2}\right)\left(\frac{D t}{d_{\mathrm{f}}^{2}}\right)^{1 / 2} \\
& \times\left(\pi^{-1 / 2}+2 \sum_{n=1}^{\infty}(-1)^{n} i \operatorname{erfc}\left(\frac{\mathrm{n} d_{\mathrm{f}}}{(D t)^{1 / 2}}\right)\right) \\
& \times 4 K\left(\frac{D t}{d_{\mathrm{f}}^{2}}\right)\left(\frac{1}{4}+2 \sum_{n=1}^{\infty}(-1)^{n} i^{2} \operatorname{erfc}\left(\frac{n d_{\mathrm{f}}}{(D t)^{1 / 2}}\right)\right)
\end{aligned}
$$

Within a relatively short period of diffusion time, i.e., $t<0.54 d_{\mathrm{f}}^{2} / D$ or $\Omega<0.82(1+K / 2)$, all the summation terms in eq 15 can be ignored, and eq 15 can be reduced to the following simplified form with an error less than $5 \%$

$$
\Omega=2\left(1+\frac{K}{2}\right)\left(\frac{D t}{d_{\mathrm{f}}^{2}}\right)^{1 / 2}\left(\pi^{-1 / 2}\right)
$$

By knowing the curvature variation ratios at various times in the initial diffusion stage, one can readily calculate the diffusion constant, $D$, according to eq 16 . On the other hand, if experimental data of $\Omega v s$. $(t)^{1 / 2}$ exhibiting linear relationship in the initial diffusion stage, the diffusion should belong to Case I. Furthermore, if the studied polymer film is so thin that $K\left(=d_{\mathrm{f}} / d_{1}\right)$ is much smaller than unity, the expression in eq 16 can be further simplified and will become the same as that in weight gain experiment.

\section{EXPERIMENTAL}

\section{Materials}

The starting materials used in this study were a dianhydride: pyromellitic dianhydride (PMDA), and three diamines: 4,4-oxydianiline (ODA), $p$-phenylenediamine (PDA), and benzidine (B). The solvent used was $N$-methyl pyrollidone (NMP). These materials were used as received.

\section{Polycondensation of Polyamic Acids}

PMDA-ODA, PMDA-PDA, and PMDA-B polyamic acids were prepared according to the method reported in the references. ${ }^{17,21,28}$ The resulted solution had a solid content of $14 \mathrm{wt} \%$. The molecular structures of the resulted polyamic acids after cured to solid imides are shown in Figure 2.

\section{Polyimide Blends}

Blends of PMDA-ODA with PMDA-PDA, PMDA-ODA with PMDA-B, and PMDAPDA with PMDA-B were obtained by mixing the resulted polyamic acids. The mixing was done under nitrogen atmosphere for $5 \mathrm{~min}$. The resulting mixed solutions were then kept frozen before use.

\section{Random Copolyimide}

A random copolyamic acid of $50 \mathrm{wt} \%$

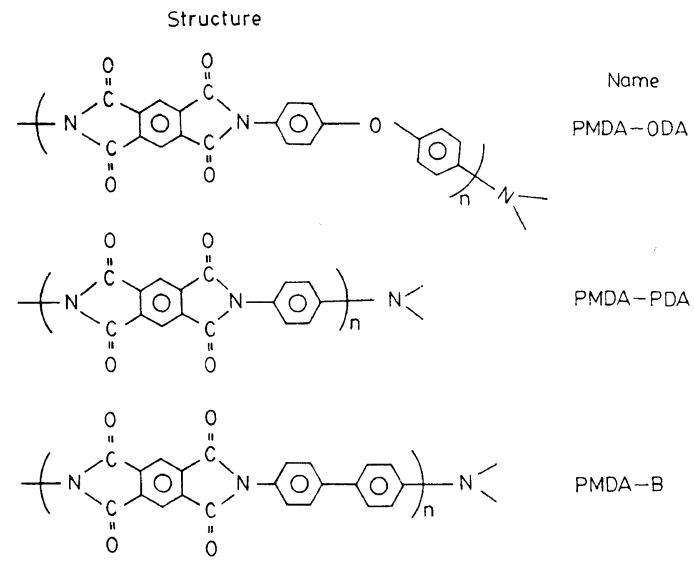

Figure 2. Molecular structures of the studied polyimides. 
PMDA-PDA with $50 \mathrm{wt} \%$ PMDA-B was prepared according to the method presented in the references. ${ }^{17,21,28}$ Similarly, two different diamines, PDA and B, were together dissolved in the NMR solvent before the the addition of PMDA.

\section{Imidization}

Solid films of the above-mentioned polyamic acids were prepared by spin-casting the solution of glass substrate and silicon strips with $7.5 \mathrm{~cm}$ in length, $0.5 \mathrm{~cm}$ in width, and $390 \mu \mathrm{m}$ in thickness. The former were used for $\mathrm{X}$-ray diffraction experiments, and the later were used for bending beam diffusion experiments. These films were then prebaked at $80^{\circ} \mathrm{C}$ for $30 \mathrm{~min}$, and curing from $80^{\circ} \mathrm{C}$ to $350^{\circ} \mathrm{C}$ in $3 \mathrm{~h}$.

\section{Bending Beam Diffusion Experiment}

Figure 3 shows schematically the experiment setup for bending beam diffusion experiments. After mounting and before measurement, each specimen was heated to $150^{\circ} \mathrm{C}$, by using a hot-air drier, for $30 \mathrm{~min}$ to remove the pre-absorbed moisture in the polyimide film. The diffusion of moisture in the polyimide film on a silicon strip was then measured in an open environment with a $55 \%$ relative humidity. Details regrading bending beam experiment can be referred to in the paper by Jou et al. ${ }^{17,21,29}$

\section{$X$-Ray Diffraction Experiment}

$\mathrm{X}$-Ray diffraction experiments were done using a Rigaku Wide-Angle X-ray Diffractometer with a nickle-filtered copper $K_{\alpha 1^{-}}$ radiation. Its power setting was at $35 \mathrm{kV}$ and $20 \mathrm{~mA}$. Details regrading $\mathrm{X}$-ray specimen preparation and experiment can be referred to in the paper by Jou et $a l .^{28}$

\section{RESULTS AND DISCUSSION}

For a $32.6 \mu \mathrm{m}$ PMDA-ODA film on a $390 \mu \mathrm{m}$ silicon substrate, the detected deflection positions of the laser beam reflected from the

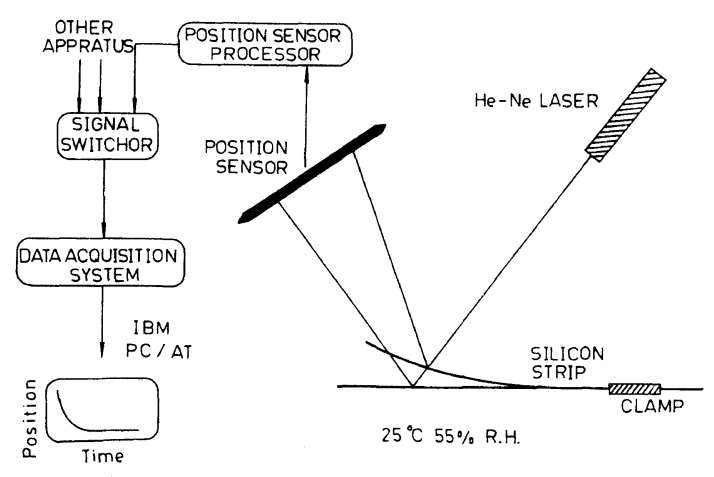

Figure 3. Schematic illustration of the experiment setup of the bending beam apparatus used for the moisture diffusion measurements.

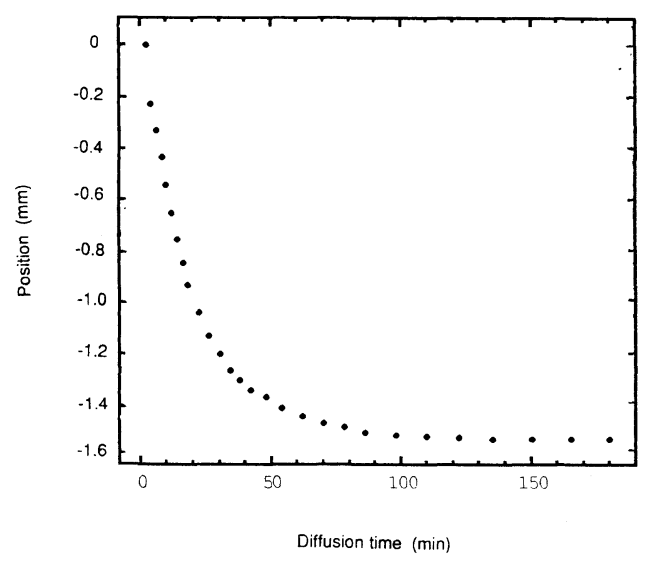

Figure 4. The measured deflection position variations at various times for the diffusion of moisture in the imide film of PMDA-ODA at room temperature and 55\% R.H.

specimen at various diffusion times are shown in Figure 4. Unlike in the determination of bending curvature or internal stress, these data can be directly converted into the corresponding curvature variation ratios, without knowing the geometric constants, such as the laser beam incident angle, sample-to-sensor distance, or sample length. The data can be converted by knowing the initial deflection position, $\delta_{0}$, and the deflection position at equilibrium, $\delta_{\infty}$, according to the relation, $\Omega=\left(\delta_{t}-\delta_{0}\right) /\left(\delta_{\infty}-\delta_{0}\right)$.

The resulting curvature variation ratio, $\Omega$, with repect to $t^{1 / 2} / d_{\mathrm{f}}$ are shown in Figure 5. 


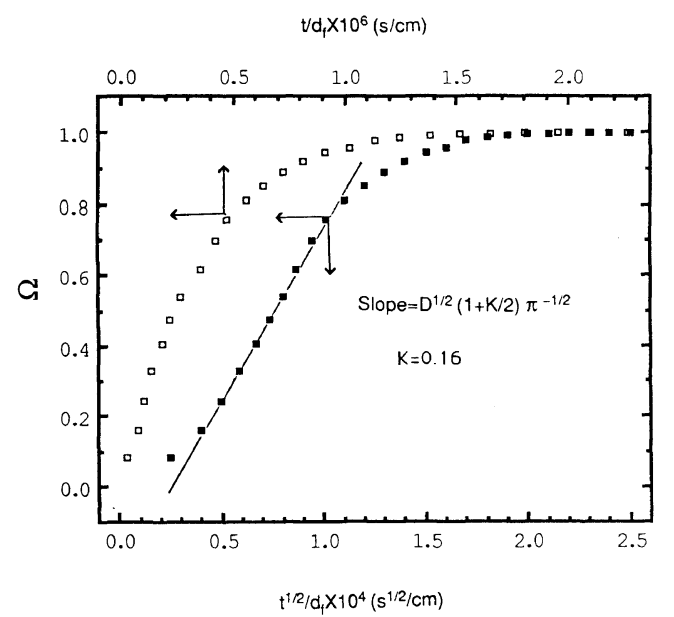

Figure 5. The converted bending curvature variation ratios at various times for the diffusion of moisture in the imide film of PMDA-ODA at room temperature and 55\% R.H.

Except the first two data points, the $\Omega$ data points for $\Omega<0.89[=0.82(1+K / 2)]$ exhibit a linear relationship with respect to $t^{1 / 2}$. In this case, $K\left(=d_{\mathrm{f}} / d_{1}\right)=0.16$. It indicates that the diffusion of moisture in the PMDA-ODA film belongs to Case I. The diffusion constant as calculated from the slope of the linear part of the data is $4.64 \times 10^{-9} \mathrm{~cm}^{2} \mathrm{~s}^{-1}$. In the initial stage, there exists an induction phenomenon. However, the induction time is relatively short.

The diffusion of moisture in a $22.0 \mu \mathrm{m}$ PMDA-PDA film is shown in Figure 6. For $\Omega<0.86$, there also exhibits a linear relationship. The diffusion constant of moisture in this rigid rod-like PMDA-PDA film is $1.25 \times 10^{-9}$ $\mathrm{cm}^{2} \mathrm{~s}^{-1}$.

The diffusion of moisture in another rigid rod-like polyimide film, i.e., a $27.0 \mu \mathrm{m}$ PMDA-B film, is shown in Figure 7. The diffusion of moisture in the PMDA-B film is also a Case I diffusion. Its diffusion constant is $0.10 \times 10^{-9} \mathrm{~cm}^{2} \mathrm{~s}^{-1}$. The relatively slow diffusion may be attributed to its relatively high crystallinity and small interchain spacing. ${ }^{28}$

In the blends of PMDA-ODA with PMDA-

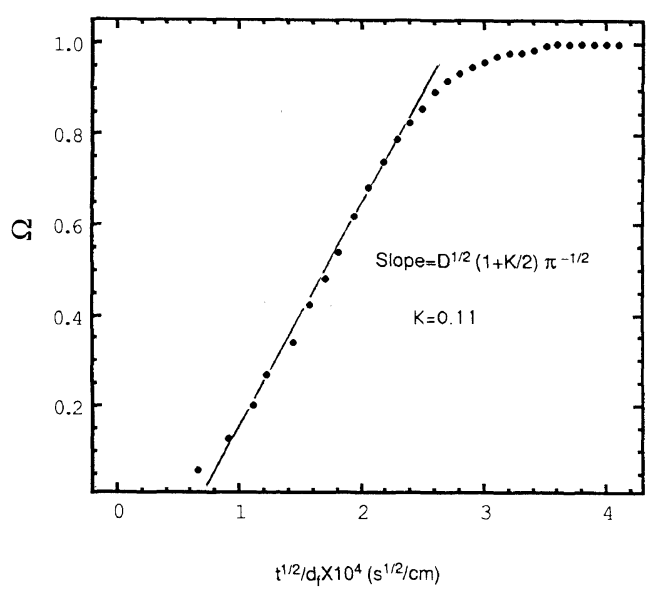

Figure 6. The measured bending curvature variation ratios at various times for the diffusion of moisture in the imide film of PMDA-PDA at room temperature and 55\% R. H.

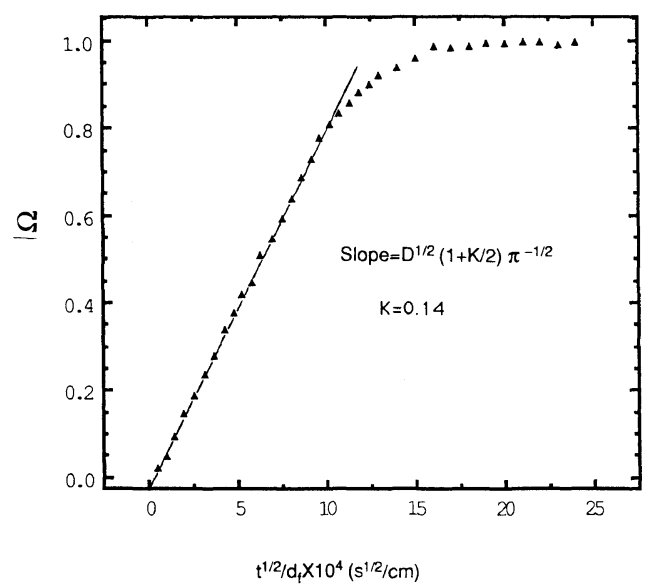

Figure 7. The diffusion of moisture in the imide film of PMDA-B.

PDA, their diffusions are shown in Figure 8. They all exhibit Case I diffusion behavior with diffusion constants of $3.30,2.70$, and $2.03 \times$ $10^{-9} \mathrm{~cm}^{2} \mathrm{~s}^{-1}$ for PMDA-ODA/PMDA-PDA weight ratios of $75 / 25,50 / 50$, and $25 / 75$, respectively. The diffusion coefficient increases with the increases of the PMDA-ODA content.

In the blends of PMDA-ODA with PMDA$B$, their diffusions are shown in Figure 9. They all also exhibit Case I diffusion behavior. 


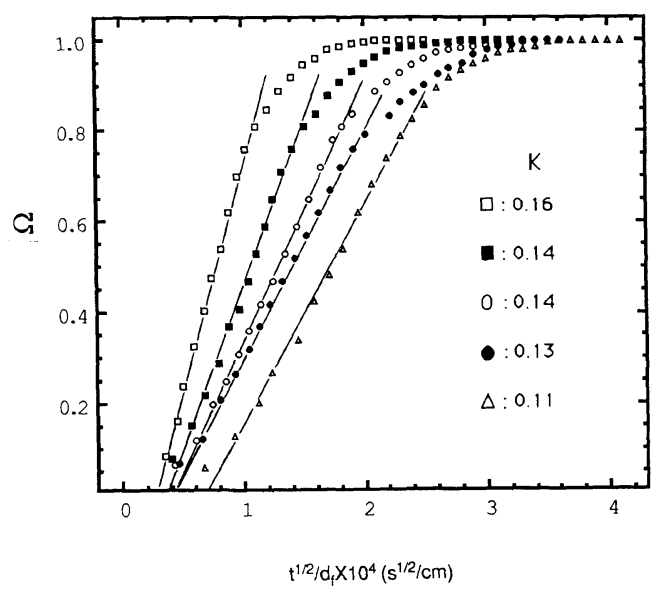

Figure 8. The diffusions of moisture in the imide films of the blends of PMDA-ODA with PMDA-PDA. ( $\square$ ) PMDA-ODA, D = 4.64 $\times 10^{-9} \mathrm{~cm}^{2} \mathrm{~s}^{-1}$; ( $) 75 \mathrm{wt} \%$ PMDAODA $/ 25 \mathrm{wt} \%$ PMDA-PDA, $D=3.30 \times 10^{-9} \mathrm{~cm}^{2} \mathrm{~s}^{-1} ;$ (O) $50 \mathrm{wt} \%$ PMDA-ODA $/ 50 \mathrm{wt} \%$ PMDA-PDA, $D=2.70 \times$ $10^{-9} \mathrm{~cm}^{2} \mathrm{~s}^{-1}$; (O) $25 \mathrm{wt} \%$ PMDA-ODA/75 wt \% PMDAPDA, $D=2.03 \times 10^{-9} \mathrm{~cm}^{2} \mathrm{~s}^{-1}$; $(\triangle)$ PMDA-PDA, $D=$ $1.25 \times 10^{-9} \mathrm{~cm}^{2} \mathrm{~s}^{-1}$.

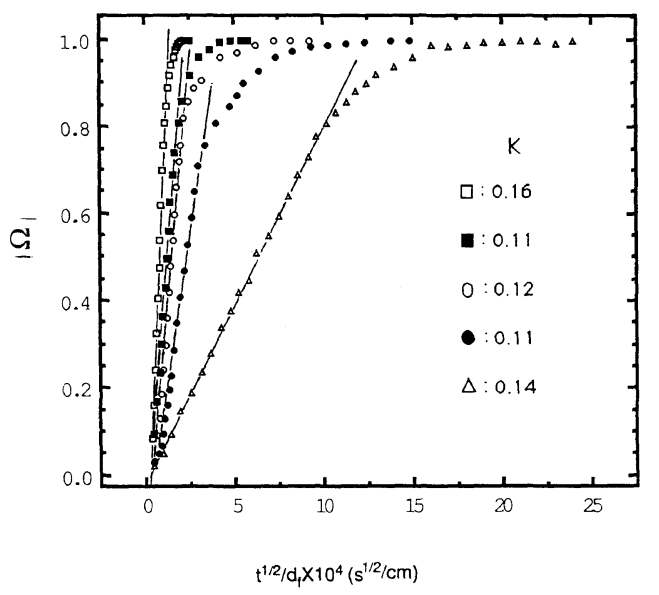

Figure 9. The diffusions of moisture in the imide films of the blends of PMDA-ODA with PMDA-B. ( $\square$ ) PMDAODA, $D=4.64 \times 10^{-9} \mathrm{~cm}^{2} \mathrm{~s}^{-1}$; (只) $75 \mathrm{wt} \%$ PMDAODA $/ 25 w t \%$ PMDA-B, $D=1.94 \times 10^{-9} \mathrm{~cm}^{2} \mathrm{~s}^{-1}$; (O) $50 \mathrm{wt} \%$ PMDA-ODA $/ 50 \mathrm{wt} \%$ PMDA-B, $D=0.69 \times 10^{-9}$ $\mathrm{cm}^{2} \mathrm{~s}^{-1}$; (○) $25 \mathrm{wt} \%$ PMDA-ODA $/ 75 \mathrm{wt} \%$ PMDA-B, $D=0.47 \times 10^{-9} \mathrm{~cm}^{2} \mathrm{~s}^{-1} ;(\triangle)$ PMDA-B; $D=0.10 \times 10^{-9}$ $\mathrm{cm}^{2} \mathrm{~s}^{-1}$.

The diffusion constants are 1.94, 0.69 and $0.47 \times 10^{-9} \mathrm{~cm}^{2} \mathrm{~s}^{-1}$ for PMDA-ODA/PMDA$\mathrm{B}$ weight ratios of $75 / 25,50 / 50$, and $25 / 75$,

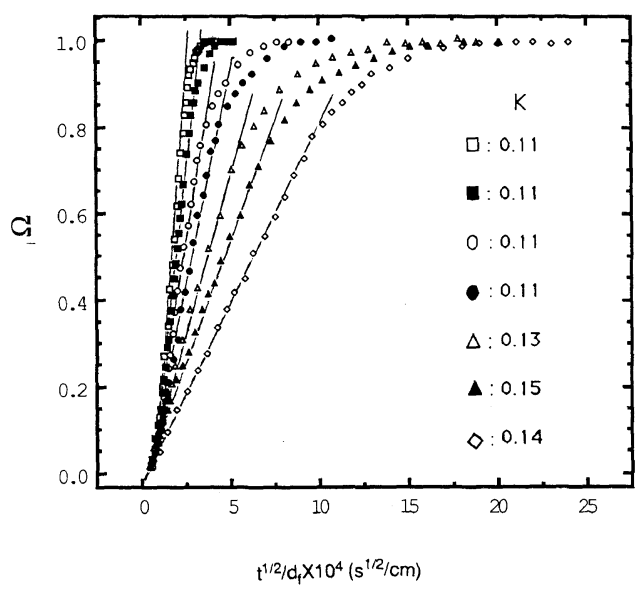

Figure 10. The diffusions of moisture in the imide films of the blends of PMDA-PDA with PMDA-B and a random copolymide of $50 \mathrm{wt} \%$ PMDA-PDA with $50 \mathrm{wt} \%$ PMDA-B. ( $\square$ ) PMDA-PDA, $D=1.25 \times 10^{-9} \mathrm{~cm}^{2} \mathrm{~s}^{-1}$; $80 \mathrm{wt} \%$ PMDA-PDA $/ 20 \mathrm{wt} \%$ PMDA-B, $D=0.70 \times 10^{-9}$ $\mathrm{cm}^{2} \mathrm{~s}^{-1}$; (O) $50 / 50$ random copolymer, $D=0.48 \times 10^{-9}$ $\mathrm{cm}^{2} \mathrm{~s}^{-1}$; (O) $60 \mathrm{wt} \%$ PMDA-B $/ 40 \mathrm{wt} \%$ PMDA-B, $D=$ $0.41 \times 10^{-9} \mathrm{~cm}^{2} \mathrm{~s}^{-1}$; (4) $40 \mathrm{wt} \%$ PMDA-PDA $/ 60 \mathrm{wt} \%$ PMDA-B, $D=0.33 \times 10^{-9} \mathrm{~cm}^{2} \mathrm{~s}^{-1}$; (A) $20 \mathrm{wt} \%$ PMDAPDA $/ 80 \mathrm{wt} \% \quad$ PMDA-B, $D=0.23 \times 10^{-9} \mathrm{~cm}^{2} \mathrm{~s}^{-1} ; \quad(\diamond)$ PMDA-B, $D=0.10 \times 10^{-9} \mathrm{~cm}^{2} \mathrm{~s}^{-1}$.

respectively.

The above two blend systems both compose the same semi-flexible polyimide and a different rigid rod-like polyimide. Figure 10 shows the diffusions of moisture in the blends composing the two different rigid rod-like polyimides, i.e., PMDA-PDA and PMDA-B. The diffusion constants of moisture in these films containing $80,60,40$, and $20 \mathrm{wt} \%$ PMDA-PDA are 0.70 , $0.41,0.33$, and $0.23 \times 10^{-9} \mathrm{~cm}^{2} \mathrm{~s}^{-1}$, respectively. As seen, the diffusions in these blends decrease with the increase of the PMDA-B content. It seems very reasonable since the diffusion of moisture in PMDA-B is much more unfavorable, relatively speaking. The slower diffusion of moisture in PMDA-B may be attributed to its smaller interchain spacing, as indicated in the paper. ${ }^{28}$ Smaller interchain spacing usually means a stronger intermolecular interaction. Consequently, it would be more difficult for water molecules to move within the PMDA-B film. 


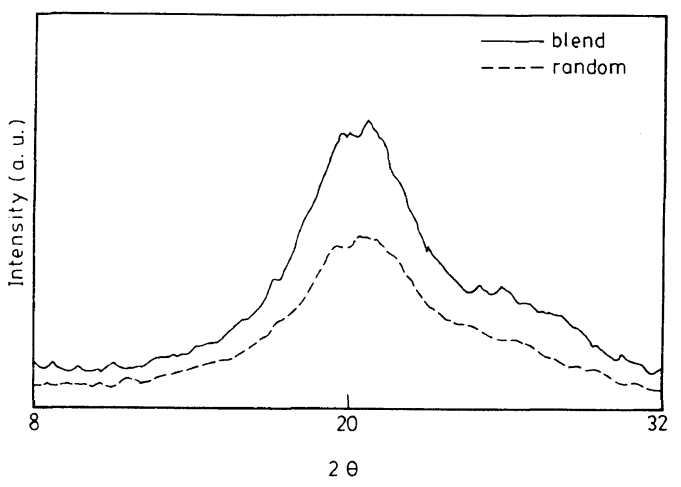

Figure 11. X-Ray diffraction patterns of the blend and random copolymer, both with $50 \mathrm{wt} \%$ PMDA-PDA and $50 \mathrm{wt} \%$ PMDA-B.

The diffusion coefficient in the film of the random copolyimide composing $50 \mathrm{wt} \%$ PMDA-PDA and $50 \mathrm{wt} \%$ PMDA-B is $0.48 \times$ $10^{-9} \mathrm{~cm}^{2} \mathrm{~s}^{-1}$. This value is higher than that in the blend containing $40 \mathrm{wt} \%$ or even $60 \mathrm{wt} \%$ PMDA-PDA. If the morphology of this random copolyimide were similar to those of the two blends, its diffusion constant should have fallen between those of the two blends. In other words, the moisture diffusion in the $50 / 50$ random copolymer might have been slower than in the blend containing $60 \mathrm{wt} \%$ PMDA-PDA, since the diffusions in the blends with more PMDA-PDA contents are faster. This result implies that the random copolyimide film must have a diffusion more favorable structure.

Figure 11 compares the out-of-plane X-ray diffraction patterns of the random copolymer and a blend with the same composition, i.e., $50 \mathrm{wt} \%$ PMDA-PDA and $50 \mathrm{wt} \%$ PMDA-B. It can be seen clarly that the random copolyimide exhibits a much weaker diffraction pattern. The presumed random copolymer is in deed more amorphous. This reveals why the moisture diffusion in the $50 \%$ PMDA-PDA/ $50 \%$ PMDA-B random copolymer is even faster than that in the $60 \%$ PMDA-PDA/ $40 \%$ PMDA-B.

\section{CONCLUSION}

In this study, a theoretical model correlating the bending curvature variation ratio of a layered structure caused by moisture-induced-swelling in its polymer overcoat with diffusion time under Case I diffusion has been presented. This model has also taken into account the pre-existed intrinsic strain in the polymer film upon deposition and/or curing. According to this model, any specimen to be studied needs not be bending or strain free. This makes the model more useful. By using this model and the bending beam technique, one can easily identify if a given diffusion is Case I. In case of Case I, one can readily calculate the corresponding diffusion constant by using the simple approximated formula mentioned above. The diffusion constant can also be obtained on a trial-and-error basis from a numerical curve fitting using another exact formula.

According to this model, all the diffusions of moisture in the films of three polyimides, their blends, and a random copolyimide belong to Case I. In the PMDA-ODA film, the diffusion constant is $4.64 \times 10^{-9} \mathrm{~cm}^{2} \mathrm{~s}^{-1}$. In PMDA-PDA, it is $1.25 \times 10^{-9}$, and in PMDA-B $0.10 \times 10^{-9} \mathrm{~cm}^{2} \mathrm{~s}^{-1}$. Among the three polyimides, the fastest moisture diffusion in PMDA-ODA can be attributed to its amorphous film structure. In the blends of PMDA-ODA with PMDA-PDA and PMDAODA with PMDA-B, the diffusion constants increase with the increase of PMDA-ODA content. In the blends of PMDA-PDA with PMDA-B, the diffusion constants increase with the increase of PMDA-PDA contents. Comparing with PMDA-PDA, PMDA-B is moisture diffusion more unfavorable. This may be attributed to its smaller interchain spacing. The diffusion in the film of a random copolymer with $50 \mathrm{wt} \%$ PMDA-PDA and $50 \mathrm{wt} \%$ PMDA-B is even faster than in the blend with $60 \mathrm{wt} \%$ PMDA-PDA and $40 \mathrm{wt} \%$ PMDA-B. This can be attributed to the fact that the 
random copolyimide film is more amorphous than its corresponding blend according to an $\mathrm{X}$-ray diffractometry study.

Acknowledgments. This work has been supported by the National Science Council, Taiwan, R.O.C., through projects, NSC790405-E007-25 and NSC-80-0405-E007-13.

\section{REFERENCES}

1. N. Adrova, N. I. Bessonov, I. A. Layus, and A. P. Rudakov, "Polyimide: A New Class of Thermostable Polymers", Technomic, Newport, CT, 1970.

2. C. E. Sroog, J. Polym. Sci., Macromol. Rev., 17, 2583 (1976).

3. M. Terasav, S. Minami, and J. Rubin, Int. J. Hybrid Microelectron, 6, 607 (1983).

4. T. Watari and H. Murano, IEEE Trans. Component Hybrid Manuf. CHMT-8, 462 (1985).

5. Y. K. Lee and J. D. Craig, "Polymer Material for Electronic Application," ACS Symposium Series No. 184, The American Chemical Society, Washington D. C., 1982, p. 107.

6. A. Saiki, K. Mukai, and S. Harada (Hitachi, Ltd.), Polymer Material for Electronic Application, ACS Symposium Series No. 184, The American Chemical Society, Washington, D. C., 1982, p 123.

7. S. T. Chen, C. H. Yang, F. Faupel, and P. S. Ho, J. Appl. Phys., 64, 6690 (1988).

8. T. Techangai, Y. Segui, and K. Doukkali, J. Appl. Polym. Sci., 38, 305 (1989).

9. J. C. Wood, Corrosion-NACE, 34, 70 (1978).

10. E. Sacher, IEEE Trans. Electr, Insul., EI-14, 85 (1979).
11. C. Y. Hui, K. C. Wu, R. C. Lasky, and E. J. Kramer, J. Appl. Phys., 61, 5129 (1987).

12. C. Y. Hui, K. C. Wu, R. C. Lasky, and E. J. Kramer, J. Appl. Phys., 61, 5137 (1987).

13. E. Gattiglia and T. P. Russell, J. Polym. Sci., Polym. Phys. Ed., 27, 2131 (1989).

14. H. M. Tong and K. I. Saenger, J. Polym. Sci., Polym. Phys. Ed., 27, 689 (1989).

15. H. M. Tong and K. I. Saenger, J. Plast Film Sheeting, 4, 308 (1988).

16. R. M. Yang and H. M. Tong, J. Polym. Sci., Polym. Lett. Ed., 23, 583 (1985).

17. J. H. Jou and L. Hsu, to appear, J. Appl. Polym. Sci.

18. D. D. Denton, D. R. Day, D. F. Priore, S. D. Senturia, E. S. Anolick, and D. Scheider, J. Electon. Mater., 14, 119 (1985).

19. B. S. Berry and W. C. Pritchet, IBM J. Res. Dev., 28, 662 (1984).

20. D. K. Yang, W. J. Koros, H. B. Hopfenberg, and V. T. Stannett, J. Appl. Polym. Sci., 30, 1035 (1985).

21. J. H. Jou, R. Huang, and W. P. Shen, to appear, $J$. Appl. Polym. Sci.

22. Z. C. Feng and H. D. Liu, J. Appl. Phys., 54, 83 (1983).

23. X. Gui, W. C. Wu, and G. B. Gao, ACTA Electronica Sinica, 14, 123 (1986).

24. J. H. Jou, IBM-RJ (Physics), 6058 (1988).

25. J. H. Jou, L. Hsu, and S. L. Chang, to appear, Thin Solid Films.

26. K. Inoue and S. Hoshino, J. Polym. Sci., Polym. Phys. Ed., 14, 1513 (1976).

27. J. Crank, "The Mathematics of Diffusion" 2nd ed, Oxford University Press, Ely House, London W. 1, 1975, Chapter 2, p 4.

28. J. H. Jou and P. T. Huang, Polym. J., 22, 909 (1990).

29. J. H. Jou, J. Hwang, and D. C. Hofer, IBM-RJ (Physics), 5984 (1987). 